\title{
Reflections on the Language of Rights from a Queer Perspective
}

\author{
Jaya Sharma*
}

\section{Introduction}

Rights language can be used in a myriad of ways. As Alice Miller (2004) argues, the manner in which rights are claimed can range from being status quo-ist to being transformatory. There has, however, been insufficient reflection and dialogue regarding the limitations of rights language. Too often there has been an unquestioning acceptance that rights language will always ultimately promote the quest for justice.

The reflections shared in this article draw upon my experiences as a member of PRISM (People for Rights of Indian Sexuality Minorities), a queer activist forum based in New Delhi, India, which works on issues related to same sex sexualities. ${ }^{1}$ This is a context in which many 'progressive' movements still view sexuality as a 'luxury' cause, one not to be prioritised. PRISM has sought to highlight the ways in which a range of dominant ideologies and institutions (such as those relating to patriarchy and religious fundamentalism) deploy constructions of sexuality to maintain inequitable distribution of power, resources, suffering, pleasure and spaces, to the detriment of full and free expression of human sexuality and people's human rights. PRISM's work seeks to bring into question basic notions and norms of sexuality. It seeks to problematise enforced heterosexuality and heteronormativity and the idea that sexual identity and behaviour is fixed from birth, and focuses on issues relating to same sex desire and gender transgression. We seek to make these issues visible in mainstream society, to respond to human rights violations, and to engage progressive movements with issues of marginalised sexualities as an intrinsic part of their mandate.

In PRISM, we have used the language of rights to demand legitimacy and freedom from violations faced by same sex desiring people, particularly vis-àvis the state. However, many of us find that the rights discourse is insufficient to articulate and act upon a queer feminist perspective on sexuality. In this article, I draw on experiences from PRISM's work and discussions within the forum with other activists to examine the language of rights from a queer perspective. $^{2}$ I seek to unpack some of the underlying premises of rights language and the directions that these premises push us towards when it is deployed. I explore the limits of rights language in the context of the realities and needs of queer activism, especially in relation to dialogue with other progressive groups. The article suggests that the articulation of queer issues only in terms of rights might limit the discourse on same sex desire, and that alternative, feminist framings might offer more potential for developing strategies for achieving justice and equity.

\section{Queer thoughts on the rights language 2.1 The issue of identity}

Talk of rights by a range of players in the Indian context - including people's movements, nongovernmental organisations (NGOs) and the state is almost always in terms of identities based on gender, race, ethnicity, class, dis/ability, age, sexual orientation, etc. Even when broader terms such as human rights and sexual rights are used, the manner in which they are drawn upon is in terms of identities. For example, when human rights are evoked, it is the human rights of particular sections of society that are demanded, such as the human rights of tribal people, children, women, etc. There could be other ways of evoking human rights. As Susan Jolly commented in her response to a draft of this article, heteronormativity itself could be argued to be a human rights violation! Yet rights are almost never articulated in this manner. 
An intervention was made by PRISM during the 16 days of 'Activism against Violence Against Women' three years ago. PRISM raised the issue of lesbian suicides with the womens' organisations who were part of the campaign. ${ }^{3}$ In the previous four months, there had been at least three cases of lesbian suicides reported in the press. The response of the women's groups to raising the issue of lesbian suicide was positive. They said, 'Why don't you raise the issue and we will support you'. We in turn asked the women's groups whether the issue of lesbian suicides was not intrinsic to the agenda of the women's movement. It was this approach that was articulated in the leaflet that was then jointly brought out by PRISM and a number of organisations including womens' groups.

After sharing the three cases of lesbian suicides the leaflet stated:

'Apart from rape, sexual harassment, and bride burning, violence against women happens every time a woman is married against her will. It happens every time a woman feels guilty for wanting to be happy and every time that a woman must die because she is unacceptable to society.

Lesbian suicides are a result of society's attempt to restrict women's choices and control their lives.

We protest these Deaths as Violence Against All Women'.

Even in the case of sexual rights, while the concept itself is a universalistic one, in the manner in which I have encountered it in dialogue or negotiations, there is a tendency to articulate these rights as they relate to specific groups, such as 'sexual minorities', 'women' or 'sex workers'. The potential that the language of sexual rights holds to cut across identities is most often not drawn upon in the manner in which even activists engaged with issues of sexuality use the term.

That the logic of rights pushes us into a framework based on identities is a source of concern, particularly in the context of same sex desire. At the outset, it needs to be clarified that there is no denying that the assertion of identities is important, particularly in a context such as that in India, where there is such silence around same sex desire. Identities are also important in order to be able to experience a sense of belonging to a community, the value of which cannot be underestimated, particularly in the face of severe stigma and isolation. It needs to be underlined therefore, that the concerns outlined below do not constitute a rejection of identities based on sexual behaviour. It is however important to recognise that identities capture one aspect of the existing reality with respect to same sex desire and the dangers of assuming that it is the entire reality.

More often than not, the assumption made by activists in contemporary urban India who address issues related to same sex desire, including a vast majority of activists who identify as lesbian, gay, bisexual or transgender (LGBT), is that sexual behaviour necessarily translates into identities based on that behaviour. Therefore, for example, the assumption is that every woman who experiences desire for women will identify/can be identified as a lesbian. In the Indian context, we know however that the number of people who identify as LGBT or even as indigenous identities such as kothi, aravani and jogappa, which each have their own sets of norms related to gender expression and sexual behaviour, is much smaller than the number of people who experience same sex desire.

It is not only a question of numbers. The issue is a more basic one of how sexuality is being understood. Speaking of sexuality only in terms of identities promotes a view that sexuality is fixed and that it can be fitted into mutually exclusive categories. We need to consider here a queer perspective of sexuality, according to which social processes of compulsory heterosexuality seek to stifle sexual diversity - not just in society at large, but even the potential for sexual diversity within each of us. If this is how we perceive sexuality, the dangers of a framework that is based only on identities become clear. If this is premised on pre-defined communities based on sexual orientation, we are faced with the issue of excluding those who do not identify and of promoting a view of sexuality that is rigid. 
Prayas, a 'high-profile' child rights organisation based in New Delhi, in a concept note that it circulated in 2003 on Legalising Homosexuality stated:

'Freedom does not mean license. Injectible Drug Users (IDUs), organised Commercial Sex Workers (CSWs), or Men having Sex with Men (MSM) can hardly take recourse to Fundamental Rights to persist in their behaviour unhindered.

It is erroneous and imprudent to say that we have a 'gay community'. There are present hardly any of the accepted prerequisites of community. At best, gays make for a small discrete group of freaks or perverts. It would be unwise to ignore larger interests of society, in order to cater to the whims of these disparate microscopic groups.

It is incorrect to assume that homosexual behaviour is not "unnatural". It is just not there in other species. It is not the natural order. Clandestine and subterranean, homosexuality cannot be taken to be in consonance with Human Rights'.

\subsection{Intersectionality instead of 'othering'}

The discussion on rights and identity has another specificity when it comes to same sex desire. In the case of race, caste or disability, there are clear markers of identity. However, as a queer perspective sees everyone as having potential for a diversity of sexual desire, including same sex desire, it is difficult to draw boundaries. This in my view generates anxiety within those who identify as heterosexual in a manner that makes queer activism all the more challenging. In this context it becomes much easier, even for those who are liberal, to speak in defence of the rights of the 'other'. The language of rights then provides a safe distance with which to deal with same sex desire.

Queer politics challenges this tendency to distance oneself from the issue. Instead it pushes other progressive individuals and movements to recognise the logic of incorporating issues of queer sexuality as being part of their own agenda. It is only by situating rights within the framework of intersectionality that this deeper alliance building becomes possible. Such a framework articulates the fundamental linkages between the norms and structures related to compulsory heterosexuality, patriarchy, racism, casteism, religious fundamentalism and other ideologies that seek to define and control people. It recognises that any attempt to isolate one dimension will constitute a limited approach that fails to address the underlying interplay of forces.

\subsection{How can you claim human rights if you are not considered human?}

In addition to the limitations of a narrowly defined rights approach in building deeper alliances, there are also limitations in the capacity of such an approach to address the attitudes of those who are hostile to same sex desiring people. In a context in which queer sexuality is despised by many and also criminalised, rights language does not take us very far in the process of claiming justice. For hostile players to even grant that homosexuals are 'human', and therefore should enjoy 'human rights', becomes difficult. In more liberal contexts, there are those who grant that homosexuals, like other people, have rights that should not be violated. However, even here, if the discomfort and moral judgment against same sex desire is not addressed, a mere assertion of rights will not suffice. There is no shortcut to engaging with underlying beliefs and values.

\subsection{Addressing heteronormativity}

Another danger related to the rights language is that the way in which rights are articulated and claimed might not address underlying structural inequalities and norms. In the case of queer sexuality, this failure to address underlying norms is fatal. The nature of violations, experienced by same sex desiring people, are often not of a tangible nature. These include the silence around same sex desire, in contexts such as India. Due to this, same sex desiring people often feel, before/if they come into contact with others 'like them', that they are 'the only ones in the world' who are this way. The relentless assumption and assertion of heterosexuality as the only reality, continuously marginalises and seeks to invalidate the experience of same sex desiring people. If we were to focus only on more tangible violations, as the existing rights discourse pushes us to do, everyday, ongoing violations would be difficult to articulate or address. 
A gender and sexuality training course was conducted by a New Delhi-based organisation that works on gender and education. The participants were non-formal education teachers involved in an educational intervention in rural Rajasthan. One of the 'fun' activities included antakshiri (a song-based game in which participants divide up into teams and have to sing, picking up on the last letter of the alphabet of the song sung by the opposing team). The men were on one side and the women on the other, singing romantic songs addressed to each other. While the activity was aimed at reducing some of the inhibitions related to sexuality, it was highly heteronormative. The experience was similar to the kind of heteronormative humour that is often exchanged with colleagues in workspaces.

Heteronormativity needs to be centrally addressed because all violations related to queer sexuality, tangible or intangible, stem from the threat that same sex desire poses to existing norms and structures relating to compulsory heterosexuality. It is because of the perceived threat to societal norms that uphold heterosexuality that the violations that accrue are so severe.

The rights language however, does not help 'unpack' heteronormativity - i.e. why these norms exist; how they serve the interests of existing power structures; and how these norms might be challenged. In fact, the language of rights and the related language of choice can sometimes take us away from addressing the underlying issues. For example, it runs the danger of limiting the issue of queer sexuality to the realm of 'personal' choice. This danger is compounded by the fact that the space that the rights discourse has historically occupied has been one of the individual, located in a liberal framework. Feminist critiques of the limits of law and human rights, by which we are all made rights holders, also point to the illusory nature of choice. These critiques also point to the related danger of the oversimplification of power relations. In the context of compulsory

heterosexuality, the extent to which choice and rights can be exercised is severely limited, given the constraints to recognising or acting upon the diversity of desire within us.

The limitations of rights language in addressing heteronormativity are similar to the ones outlined in the discussion on intersectionality, i.e. that rights language by itself does not offer the tools that can enable an analysis of how different axes such as gender, sexuality, class and so on intersect. It appears to me therefore that rights language is precisely that - a language, more than an 'approach' or an 'ideology' - in itself.

\subsection{Side-stepping subversion}

That rights language does not generally engage with heteronormativity also means that it almost never engages with the subversive potential of queer sexuality. An important manifestation of this lack of engagement is the focus of rights language, in the manner in which it is most often deployed, on violations. In the context of same sex sexuality, we find that it is sometimes easier for us as activists (whether same sex desiring or not) who are engaged with these issues to restrict the discourse to violations, and to generate a more limited consensus around these. On the part of others, too, there is a preference for limiting the engagement to violations of human rights. There is a reluctance to recognise and concede to the subversive potential that queer desire holds, which comes from the structures and ideologies that are threatened. Part of this reluctance also needs to be located in the anxieties that a deeper engagement with issues of same sex desire generates, given middle class (the background of the majority of the activists that PRISM has thus far engaged with) construction and experience of sexuality as an intensely personal, intimate realm.

\section{Conclusion}

This article has sought to highlight some of the premises underlying the language of rights and their implications, such as the dangers of being pushed into using a limiting framework of identities based on sexual orientation. Another set of implications relate to the nature of engagement with other progressive movements with queer issues. In a context in which there are fears and anxieties about a closer engagement with these issues, the rights language can allow others to offer support from a 'safe' distance. The article has also sought to draw attention to the limitations of rights language in taking account of intersectionality, which is required to undertake alliance-building efforts that are more deep rooted. Similarly, its limitations in terms of unpacking and therefore challenging 
A resolution was sought to be passed at the Indian Association of Women's Studies (IAWS) conference in Goa in May 2005. The theme of the conference was 'Sovereignty and Citizenship'. The resolution was drafted by feminist, queer (both same sex and other sex desiring) individuals, including an activist who also works on issues of disabilities. The resolution was as follows.

'We in the women's movement have long recognised that constructions of what is "natural" and "normal" have been used to define and control us as women. We also recognise that rigid binaries of "man" and "woman", notions of what constitutes a "normal" body and notions of what constitutes "acceptable" sexual behaviour limit possibilities for all of us. They also stigmatise and deny citizenship rights to individuals and communities perceived to deviate from the "normal". These include, for example, people with disabilities, those who are same-sex desiring, lesbian and bisexual women, transgendered people, hijras and sex workers.

In this context, Section 377 of the Indian Penal Code clearly violates every principle of equity, justice and citizenship. Section 377 criminalises a wide range of non-procreative sexual acts considered to be "against the order of nature". This provision is justified on the grounds that it provides legal redress against child sexual abuse. However, not only is it entirely inadequate in this regard, in practice it is used to harass, control and criminalise those who threaten patriarchal structures upheld by compulsory heterosexuality. We call upon the government to repeal Section 377 and to ensure that a separate law be enacted at the earliest to effectively deal with child sexual abuse. Legal provisions such as Section 377 violate the letter and spirit of the Fundamental Rights enshrined in the Constitution which guarantee equality and freedom to all citizens.

IAWS commits to engaging with the experiences and emerging perspectives that communities perceived to deviate from the "normal' offer to the women's movement. Such an engagement would enable us to subvert and strike at prescriptive norms. It would also help evolve a framework of citizenship which is not merely a liberal framework of inclusion but one which is transformatory and liberatory'.

The only opposition to the resolution came from a member of AIDWA, a leftist party's women's wing, who said that the section of the resolution on Section 377 should remain but the section relating to the subversive potential of queer politics should be deleted from the resolution.

heteronormativity have been highlighted. In fact, a narrow use of rights language offers an escape from addressing heteronormativity and its subversion.

I would like to reiterate here that I believe it is possible to use the language of rights and to address intersectionality, heteronormativity and subversion at the same time, and that is how effective claimmaking needs to be undertaken. The IAWS resolution quoted above made an effort to use the language of rights in this manner. In order to work with a framework of intersectionality, to address heteronormativity and to highlight the subversive potential of sexual desire, we need to draw upon feminist and queer politics. The use of rights language comes into play in a full manner to make a claim only after such an engagement has been undertaken.
It is only queer/feminist ideological and analytical frameworks that have helped us as activists draw out the linkages between oppressions. As argued above, although the rights discourse provides us with important concepts such as the 'indivisibility of rights', it does not enable us to analyse precisely how these forces intersect to define and control the realities of our lives. Similarly, it is only the conceptual framework provided by queer politics that enables us to analyse and challenge heteronormativity and the social structures that uphold it and deem same sex desire 'abnormal' or illegitimate. Heteronormativity is so pervasive, insidious and often intangible that it cannot be challenged only as 'a violation of sexual rights'. A queer articulation challenges and seeks to subvert the foundational norms of society - rather than focusing only on violations of rights. 
More recent feminist critical engagement with rights language has highlighted the limitations of such a framing with respect to justice for women. I would argue that in the realm of queer sexuality, the critiques of status quo-ist rights discourses acquire even greater significance and that the advantages of rights language are more difficult to enjoy. Despite these limitations, the language of rights has made a significant contribution to the struggle for justice in a

\section{Notes}

* This article draws upon ongoing discussions within PRISM on the rights language. Discussions with other activists and academics have been extremely valuable in formulating the arguments presented here. In particular, I would like to acknowledge the insights of Madhu Mehra, a feminist human rights advocate and Dr Uma Chakravarthy, a feminist historian and civil liberties activist.

1 PRISM is a non-funded, non-registered, queer, feminist forum of individuals based in Delhi, India. PRISM is inclusive of all gender and sexual expressions and identities. It works towards raising issues relating to same sex sexualities that fall outside the heterosexual norm, and to interrogate the norm itself.

\section{Reference}

Miller, Alice (2004) 'Sexual Rights, Conceptual Advance: Tensions in Debate' presented at the 'Sexual, Reproductive and Human Rights Seminar' organised by CLADEM, in Lima, Peru context in which same sex desire is marked with silence, stigma and violations. We need however to be more specific in our analysis of its contribution in our struggle against heteronormativity. There is also a need to draw upon rights language strategically, while being firmly rooted in a queer, feminist framework that can offer more effective and liberating discourses and strategies for justice and equity.

2 By a 'queer perspective', I mean one which recognises the dangers of narrowly defined identity politics, challenges heteronormativity and locates itself in a framework of 'intersectionality', which takes account of the connections between different types of struggles and the interplay of multiple identities. Being queer is not the same as having same sex sexual desires; a same sex desiring person will not necessarily subscribe to queer politics, just as an opposite sex desiring person could, because of the nature of their politics, have a queer perspective.

3 There have been many such cases of young women who are driven to entering into a suicide pact with their lovers. These suicides are often in a situation in which the women are being pressured by their families to get married to men. 